\title{
Antenatal Complications in Grand Multipara Presented at Tertiary Care Hospital
}

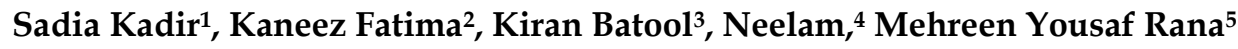

1 Consultant Gynecologist, Department of Gynecology, Suleman Roshan Medical College, Tando Adam Pakistan

1 Principal investigator, Manuscript writing, Drafting

2 Consultant Gynecologist, Pakistan Institute of Medical Sciences - PIMS, Islamabad Pakistan

Data collection

3 Consultant Gynecologist, Department of Gynecology, Shah Bhittai Hospital, Hyderabad Pakistan

3 Data interpretation

4 Consultant Gynecologist, Department of Gynecology, Shaikh Zayed Hospital, Rahim Yar Khan Pakistan

Tabulation, Data collection

5 Assistant Professor, Gynae and OBS Department, Ziauddin Hospital, Karachi

5 Statistical analysis

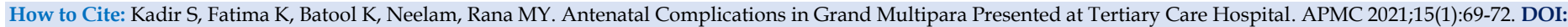
10.29054/APMC/2021.862

\section{ABSTRACT}

Background: Grand multiparity considered as a risk factor of obstetrics because of the recorded complications linked to the condition. Grand multiparity typically considered as the distinctive reason for the raised, maternal and fetal morbidity and mortality because of expanded incidence of adverse outcome during pregnancy and birth. Objective: To determine frequency of antenatal complications in grand multipara. Study Design: Cross-sectional study. Settings: Department of Obstetrics and Gynecology, Jinnah Postgraduate Medical Centre, Karachi Pakistan. Duration: Study duration was six months from March 2016 September 2016. Methodology: Total 212 patients were included in this study. Anemia was taken as $\mathrm{Hb}$ of $11 \mathrm{~g} / \mathrm{dl}$, PIH was taken as BP of $>140 / 90 \mathrm{mmHg}$ after 20 weeks of gestation with or without proteinuria on two or more occasion 6 hours apart and placenta previa was confirmed via ultrasonography. All the information was collected via

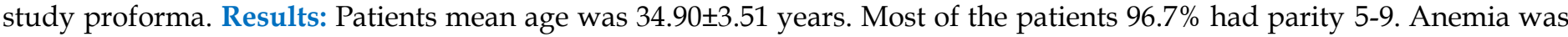
found $69.8 \%$ and pregnancy induced hypertension was $22.2 \%$, while placenta previa was found to be $18.9 \%$. Antenatal complications including anemia, pregnancy induced hypertension and placenta previa were found to be statistically insignificant according to age, parity and BMI, $(p->0.05)$. Conclusion: Most common antenatal complication in this study was anemia followed by hypertension and placenta previa. Grand multiparity is at a greater risk of antenatal complications.

Keywords: Grand Multipara, PIH, Placenta previa, Anemia.

\section{INTRODUCTION}

The concept of grand multiparity (GMP) was introduced during the last century. ${ }^{1}$ In the developing nations prevalence of the grand-multiparity is about $10 \%$ to $30 \% .2,3$ However incidence of it including its complications is $44 \%$ to $56 \%$ which is remains still higher in the Pakistan. ${ }^{2,4}$

Numerous studies have described grand multiparity as an independents risk for many maternal and fetal complications. ${ }^{1}$ In the literature particularly possible complications of the grand multiparity had been demonstrated, including pre-eclampsia, placenta previa, birth defects, gestational diabetes, multiple pregnancy prolonged labour, malpresentation, uterine rupture, postpartum hemorrhage, increased rate of the cesarean section, uterovaginal prolapse and sepsis. ${ }^{1,6-8}$

As per previous concept, elevated uses of the contraceptives and enhanced health care birth are both predictable to decrease the incidence of grand multiparity and its related complications, ${ }^{9}$ consequently, the current improvement in family planning awareness and the contraceptive uses in the population is probable to affect grand-multiparity and its linked complications. Postpartum anemia, puerperal sepsis, postpartum hemorrhage and urinary tract infections were the postpartum complications observed among grandmultiparous population as per previously published studies. ${ }^{1-4,10}$

Antenatal complications like hypertensive diseases in pregnancy, placenta previa and medical illnesses are found to be commoner in the grand-multiparous, and this agrees with previous studies. ${ }^{1-3}$ In one study, frequency of antenatal complications in grand-multipara was determined and they observed that PIH was found to be $27.1 \%$, anemia $22.2 \%$, placenta previa $15.3 \% .{ }^{11}$ Most of studies done on such subject are on retrospective data and 
as data taken from records has less worth as compare to prospective collection of data, therefore, outcome of previous studies controversial. Therefore, this study has been designed to assess current frequency of antenatal complications in grand-multiparous women. Furthermore, measures can helpful to teach and guide women to reduce number of parity and prevent these complications.

\section{METHODOLOGY}

Study Design: Cross-sectional study.

Settings: Department of Obstetrics and Gynecology, Jinnah Postgraduate Medical Centre, Karachi Pakistan.

Duration: Study was carried out over a period of six months from 21-03-2016 to 20-09-2016.

Sample Technique: Non-probability, consecutive sampling technique was used.

Sample Size: Sample size came out as 212 using Raosoft sample calculator software, confidence interval taken as $90 \%$, percentage of pregnancy-induced hypertension taken as $27.1 \%, 11$ and absolute precision as $5 \%$.

Inclusion Criteria: Women with $>28$ week of gestation, age 25-40 year and grand multipara were included.

Exclusion Criteria: All the women with pre-existing hypertension, blood disorders; leukemia, thalassemia, aplastic anemia, obese and diabetes mellitus were excluded.

Data Collection Procedure: Informed and written consent was taken from patients. On admission patients history was taken in detail. Age, gravida, parity, detailed obstetrical history, past history was recorded. Anemia was taken as hemoglobin of $11 \mathrm{~g} / \mathrm{dl}$, PIH was taken as blood pressure of $140 / 90 \mathrm{mmHg}$ after 20 weeks of gestation with or without proteinuria on two or more occasions 6 hours apart and placenta previa was taken as painless, bright red vaginal bleeding further confirmed with ultrasonography and frequency of these antenatal complications were noted. Proforma attached was filled accordingly.

Statistical Analysis: All data was analyzed using SPSS Statistics 20.0 software. Numerical variables were computed in the form of mean and standard deviation. Categorical data like antenatal complications; anemia, pregnancy induced hypertension and placenta previa was computed in the form of frequency and percentage. Stratification was done to control effect modifiers like age, BMI and parity. Chi square test was applied by taking p-value $<0.05$ was considered statistically significant.

\section{RESULTS}

Patients mean age was $34.90 \pm 3.51$ years and 36 to 40 years age group was most common. Most of the patients $96.7 \%$ had parity5-9 and 3.3\% had parity $>9$. Out of all $67.9 \%$ had BMI 21-24 and 32.1\% had BMI 32.1\%. Table 1
As per antenatal complications anemia was found $69.8 \%$ and pregnancy induced hypertension was $22.2 \%$, while placenta previa was found to be $18.9 \%$. Table 1

Table 1: Demographic characteristics and complication of the patients $(n=212)$

\begin{tabular}{|c|c|c|c|}
\hline \multicolumn{2}{|c|}{ Variables } & Number & Percentage \\
\hline \multirow{3}{*}{ Age groups } & $25-30$ & 29 & 13.7 \\
\cline { 2 - 4 } & $31-35$ & 81 & 38.2 \\
\cline { 2 - 4 } & $36-40$ & 102 & 48.1 \\
\hline \multirow{2}{*}{ Parity } & $5-9$ & 205 & 96.7 \\
\cline { 2 - 4 } & $10-13$ & 7 & 3.3 \\
\hline \multirow{2}{*}{ BMI } & $18-20$ & 68 & 32.1 \\
\cline { 2 - 4 } & $21-24$ & 144 & 67.9 \\
\hline \multirow{2}{*}{ Anemia } & Yes & 148 & 69.8 \\
\cline { 2 - 4 } & No & 64 & 30.2 \\
\hline \multirow{2}{*}{ PIH } & Yes & 47 & 22.2 \\
\cline { 2 - 4 } & No & 165 & 77.8 \\
\hline \multirow{2}{*}{ Placenta previa } & Yes & 40 & 18.9 \\
\cline { 2 - 4 } & No & 172 & 81.1 \\
\hline
\end{tabular}

Anemia was found to be statistically insignificant according to age, parity and BMI, $(p=>0.05)$. Table 2

Table 2: Stratification of age, parity and BMI with regard to anemia $(n=212)$

\begin{tabular}{|c|c|c|c|c|c|}
\hline \multicolumn{2}{|c|}{ Variables } & \multicolumn{2}{|c|}{ Anemia } & \multirow{2}{*}{ Total } & \multirow{2}{*}{ P value } \\
\cline { 3 - 6 } & $25-30$ years & 22 & 07 & 29 & \multirow{3}{*}{0.745} \\
\hline \multirow{3}{*}{ Age groups } & $31-35$ years & 56 & 25 & 81 & \multirow{2}{*}{0.74} \\
\cline { 2 - 5 } & $36-40$ years & 70 & 32 & 102 & \\
\hline \multirow{2}{*}{ Parity } & $5-9$ & 142 & 63 & 205 & \multirow{2}{*}{0.351} \\
\cline { 2 - 5 } & $10-13$ & 6 & 1 & 7 & \\
\hline \multirow{2}{*}{ BMI } & $18-20$ & 47 & 21 & 68 & \multirow{2}{*}{0.880} \\
\cline { 2 - 5 } & $21-24$ & 101 & 43 & 144 & \\
\hline
\end{tabular}

Pregnancy induced hypertension was non-significant as per maternal age, parity and BMI $(p=>0.05)$. Table 3

Table 3: Stratification of age, parity and BMI with regard to pregnancy induced hypertension (PIH)

\begin{tabular}{|c|c|c|c|c|c|}
\hline \multirow{2}{*}{ Variables } & \multicolumn{2}{|c|}{$\begin{array}{c}\text { Pregnancy induced } \\
\text { hypertension }\end{array}$} & \multirow{2}{*}{ Total } & $\begin{array}{c}\text { p- } \\
\text { value }\end{array}$ \\
\cline { 3 - 6 } & Yes & No & & \\
\hline \multirow{2}{*}{$\begin{array}{c}\text { Age } \\
\text { groups }\end{array}$} & $25-30$ years & 07 & 22 & 29 & \\
\cline { 2 - 5 } & $31-35$ years & 18 & 63 & 81 & \multirow{2}{*}{0.958} \\
\cline { 2 - 5 } & $36-40$ years & 22 & 80 & 102 & \\
\hline \multirow{2}{*}{ Parity } & $5-9$ & 45 & 160 & 205 & \multirow{2}{*}{0.678} \\
\cline { 2 - 5 } & $10-13$ & 2 & 5 & 7 & \\
\hline \multirow{2}{*}{ BMI } & $18-20$ & 17 & 51 & 68 & \multirow{2}{*}{0.495} \\
\cline { 2 - 5 } & $21-24$ & 30 & 114 & 144 & \\
\hline
\end{tabular}


Placenta previa was also statistically insignificant according to age, parity and BMI ( $p=>0.05)$. Table 4

Table 4: Stratification of age with regard to placenta previa $(\mathrm{n}=212)$

\begin{tabular}{|c|c|c|c|c|c|}
\hline \multicolumn{2}{|c|}{ Variables } & \multicolumn{2}{|c|}{ Placenta previa } & \multirow{2}{*}{ Total } & \multirow{2}{*}{ P value } \\
\cline { 3 - 6 } & Yes & No & & \\
\hline \multirow{3}{*}{ Age groups } & $25-30$ years & 07 & 22 & 29 & \multirow{3}{*}{0.451} \\
\cline { 2 - 5 } & $31-35$ years & 12 & 69 & 81 & \\
\cline { 2 - 5 } & $36-40$ years & 21 & 81 & 102 & \\
\hline \multirow{2}{*}{ Parity } & $5-9$ & 39 & 166 & 205 & \multirow{2}{*}{0.753} \\
\cline { 2 - 5 } & $10-13$ & 1 & 6 & 7 & \\
\hline \multirow{2}{*}{ BMI } & $18-20$ & 14 & 54 & 68 & \multirow{2}{*}{0.660} \\
\cline { 2 - 5 } & $21-24$ & 26 & 118 & 144 & \\
\hline
\end{tabular}

\section{DISCUSSION}

Grand multiparity is a family burden and a risk factor for increasing antenatal and postnatal as well as maternal complications such as anemia, diabetes mellitus, hypertension, increased the rate of cesarean section and postpartum hemorrhage. ${ }^{12,13}$ In this study there was a significant association between grand multiparity and antenatal complications, $69.8 \%$ patients were anemic, $22.2 \%$ were hypertensive and placenta previa developed in $18.9 \%$. These antenatal complications are comparable in accordance with study of Afolabi and Adeyemi. ${ }^{11}$

In this study mean age of the grand multiparous women was $34.90 \pm 3.51$ years, these findings were similar to the study of Mgaya AH et all4 as the mean age of grand multiparas women was $35.15 \pm 4.8$ years. On other hand Afolabi AF et al ${ }^{15}$ also reported that, most of the cases $68.7 \%$ seen with age group of 30-39 years. In another study of Alhainiah $\mathrm{MH}$ et al16 reported that the mean age of grand multipara women was $36.9 \pm 4$ years. In this study out of all study subjects $51.9 \%$ females were $\leq 35$ years, which predicted that early age of marriage leads younger grand multiparity and which could be the risk factor for severe complications.

In this study, a higher prevalence of anemia, PIH and placenta previa were observed, among grand multipara women which is consistent with findings of a study carried out by Alhainiah $\mathrm{MH}$ et al ${ }^{16}$ as anemia, gestational diabetes and medical disease were highly significant among grand multiparous women. These findings were also similar to another study, in which showed reported that the grand multiparas women $95 \%$ had anemia and high incidence of gestational diabetes regarding obstetrical complication. ${ }^{17}$ On other hand recently Adere A et al ${ }^{18}$ observed that the females having advanced maternal age $(\geq 35)$ have six fold high risk to develop placenta previa. In another recent international study of Yimer NB et al ${ }^{19}$ observed that the several adverse pregnancy outcomes were higher in grand multiparous women. In this study there was no any significant association of age, parity and BMI with antenatal complications. Similarly, Bililign N et al ${ }^{20}$ also observed that the there was any significant association of parity with pregnancy outcomes. On other hand Akhtar R et al ${ }^{21}$ also reported that the complications associated with grand multiparity were anemia $(70.15 \%)$, Hypertension $(15 \%)$, diabetes $(10.59 \%)$ and malpresentation $(7.5 \%)$. Pregnancies among women of grand multipara have been known as the high risk of complications of pregnancy and delivery for several decades among these females. Grand multiparity is still considered as a major risk in obstetrics, which requires exacting management and perfect antenatal consideration and dynamic intercession at suitable time.22 Most of the reports argued that grand multiparas are more likely to be of old age that might be the cause for raised morbidity and the mortality. As per our clinical experience such factor is hard to be eliminated on the grounds that female age is the commonest biological event factor impacts the events of the reproduction.

\section{CONCLUSION}

A per study observations the anemia, pregnancy induced hypertension and placenta previa found to be highly prevalent among grand multiparous women. This risk can effectively reduce with good antenatal care, but it's yet accountable to the severe complications of the pregnancy, which can lead to high morbidity and mortality of the mothers and fetus.

\section{LIMITATIONS}

None

\section{SUGGESTIONS / RECOMMENDATIONS}

In communities, like Pakistan where larger families are needed it is essential to address the value of the family planning and conveyance of meticulous antenatal care.

\section{CONFLICT OF INTEREST / DISCLOSURE}

The authors have no conflicts of interest to declare. All coauthors have seen and agree with the contents of the manuscript and there is no financial interest to report.

\section{ACKNOWLEDGEMENTS}

Authors greatly acknowledge to Dr. Kamran Ali for his support, feedback and guidance in manuscript writing and processing.

\section{REFERENCES}

1. Alsammani MA, Jafer AM, Khieri SA, Ali AO, Shaaeldin MA. Effect of Grand Multiparity on Pregnancy Outcomes in Women Under 35 Years of Age: a Comparative Study. Medical Archives. 2019;73(2):92.

2. Sham N, Das PCH. Maternal complications in grand multipara. MC Karachi. 2016;22(1):38-42. 
3. Simonsen SME, Lyon JL, Alder SC, Varner MW. Effect of grand multiparity on intrapartum and new born complications in young women. Am J Obstet Gynecol. 2005;106:454-60.

4. Paliwal V, Dikhit S, Singh S. Safety of induction of labour with vaginal prostaglandins (E2) in grand multipara. Oman Med J. 2009;24:184-7.

5. Mutihir JT. Obstetric outcome of the grandmultpara in Jos, Nigeria. J Med Trop. 2005;7:14-20.

6. Yasir R, Perveen FZ, Ali L, Perveen S, Tayyab S. Grand-multiparity still an obstetric risk for developing countries. Med Chan. 2010;16:264-8.

7. Abro ST, Shaikh S, Shaikh FB, Baloch R. Obstetrical complication in grand-multiparity. Med Chan. 2009;15:53-8.

8. Kelly A, Gail L. Preterm spontaneous uterine rupture in a nonlabouring grand multipara: A case report. J Obste Gynaecol Can. 2008;30:586-9.

9. Omole-Ohonsi A, Ashimi AO. Obstetric performance in Amino Kano. Niger J Clin Pract. 2011;14:6-9.

10. Rozina Y, Fauzia P, Lubna A, Shaista P, Subhana T. Grandmultiparity still an obstetric risk for developing countries. Med Chan. 2010;16:265-7.

11. Afolabi AF, Adeyemi AS. Grand-multiparity: Is it still an obstetric risk? Open J Obstet Gynecol. 2013;3:411-5.

12. Singh SP, Chawan J, Mangla D. A descriptive study: maternal and fetal outcome of grand multipara. Int J Reprod Contracept Obstet Gynecol. 2015;4(1):219-23.

13. Alhainiah MH, Abdulljabbar HS, Bukhari YA. The prevalence, the fetal and maternal outcomes in grand multiparas women. Materia socio-medica. 2018;30(2):118.
14. Mgaya AH, Massawe SN, Kidanto HL, Mgaya HN. Grand multiparity: is it still a risk in pregnancy?. BMC pregnancy and childbirth. 2013;13(1):1-8.

15. Afolabi AF, Adeyemi AS. Grand-multiparity: is it still an obstetric risk?. Open Journal of Obstetrics and Gynecology. 2013;3:411-5.

16. Alhainiah $\mathrm{MH}$, Abdulljabbar HS, Bukhari YA. The prevalence, the fetal and maternal outcomes in grand multiparas women. Materia socio-medica. 2018;30(2):118.

17. Khatun J. Obstetrical Outcome of Grand Multipara. Journal of Bangladesh College of Physicians and Surgeons. 2016;34(4):184-7.

18. Adere A, Mulu A, Temesgen F. Neonatal and Maternal Complications of Placenta Praevia and Its Risk Factors in Tikur Anbessa Specialized and Gandhi Memorial Hospitals: Unmatched Case-Control Study. Journal of Pregnancy. 2020; Article ID 5630296:1-9

19. Yimer NB, Tenaw Z, Gedefaw A. Pregnancy outcomes in Grand multiparous women: Does parity matter? A comparative study. Ethiopian Journal of Reproductive Health. 2020;12(1):11-

20. Bililign N, Gedefaw A, Tenaw Z. Pregnancy outcomes in Grand multiparous women: Does parity matter? A comparative study. 2020;12:35-41.

21. Akhtar R, Sanodia Afridi RK, Malik NN. Frequency of maternal and fetal outcome in grand multipara women. Khyber Journal of Medical Sciences. 2018;11(3):376-9.

22. Singh SP, Chawan J, Mangla D. A descriptive study: maternal and fetal outcome of grand multipara. Int J Reprod Contracept Obstet Gynecol. 2015;4(1):219-23. 